Cite this: J. Mater. Chem. C, 2014, 2, 6395

Received 8th April 2014

Accepted 30th May 2014

DOI: $10.1039 / c 4 t c 00709 c$

www.rsc.org/MaterialsC

\title{
Poly(imide-benzoxazole) gate insulators with high thermal resistance for solution-processed flexible indium-zinc oxide thin-film transistors $\uparrow$
}

\author{
Duyoung Wee, $t^{\mathrm{a}}$ Sungmi Yoo,,$^{\mathrm{ab}}$ Young Hun Kang, ${ }^{\mathrm{a}}$ Yun Ho Kim, ${ }^{\mathrm{a}} \mathrm{Jae}-\mathrm{Won} \mathrm{Ka},{ }^{\text {*a }}$ \\ Song Yun Cho, ${ }^{a}$ Changjin Lee, ${ }^{a}$ Juwhan Ryu, ${ }^{b}$ Mi Hye Yi ${ }^{a}$ and Kwang-Suk Jang*a
}

\begin{abstract}
We prepared a poly(imide-benzoxazole) gate insulator for solution-processed flexible metal oxide thin-film transistors (TFTs). The electrical insulating property of the poly(imide-benzoxazole) gate insulator is maintained up to at least $350^{\circ} \mathrm{C}$. The $350^{\circ} \mathrm{C}$-annealed indium-zinc oxide (IZO) TFT with the poly(imidebezoxazole) gate insulator showed excellent TFT performance with the field-effect mobility of $9.2 \mathrm{~cm}^{2} \mathrm{~V}^{-1} \mathrm{~s}^{-1}$ and the on/off current ratio of $1.5 \times 10^{6}$. A flexible IZO TFT with the poly(imidebezoxazole) gate insulator was also fabricated directly on a flexible Kapton substrate. The flexible IZO TFT with the poly(imide-bezoxazole) gate insulator could be operated during bending. Before bending, the mobility and on/off current ratio were $4.1 \mathrm{~cm}^{2} \mathrm{~V}^{-1} \mathrm{~s}^{-1}$ and $4.7 \times 10^{5}$, respectively. During bending with a radius of $10 \mathrm{~mm}$, the mobility was maintained and the on/off current ratio was slightly decreased to $3.2 \times 10^{5}$.
\end{abstract}

\section{Introduction}

Recently, a great deal of attention has been paid to polymeric gate insulators for solution-processed flexible thin-film transistor (TFT) arrays and circuits. ${ }^{1-9}$ For low-cost and flexible electronics applications, solution-processable and flexible gate insulators should be used instead of $\mathrm{SiO}_{2}$ gate insulators, prepared on Si substrates by vacuum deposition. Because polymeric gate insulators can be easily printed on flexible substrates at low temperature, they are an attractive candidate for solution-processed flexible TFTs. A variety of high-performance, solution-processed flexible organic TFTs with polymeric gate insulators have been reported. ${ }^{1-7}$ However, there has been limited research on solution-processed flexible metal oxide TFTs with polymeric gate insulators.

Solution-processed metal oxide TFTs with $\mathrm{SiO}_{2}$ gate insulators have shown excellent performance with high field-effect mobility. ${ }^{10-16}$ In general, metal oxide semiconductors on $\mathrm{SiO}_{2}$ gate insulators are annealed at $200-500{ }^{\circ} \mathrm{C}$ to form a coherent interface between the semiconductor and the gate insulator. ${ }^{10-16}$ To use polymeric gate insulators for solution-processed metal oxide TFTs, they should be compatible with the process for

${ }^{a}$ Division of Advanced Materials, Korea Research Institute of Chemical Technology, Daejeon 305-600, Republic of Korea.E-mail: kjang@krict.re.kr; jwka@krict.re.kr

${ }^{b}$ Department of Polymer Science and Engineering, Chungnam National University, Daejeon 305-764, Republic of Korea

$\dagger$ Electronic supplementary information (ESI) available. See DOI: $10.1039 / \mathrm{c} 4 \mathrm{tc00709c}$

\$ These authors contributed equally to this work. metal oxide semiconductor layers. For example, in bottom-gate TFTs, polymeric gate insulators should not be damaged during the post-annealing process for metal oxide semiconductors, and they should provide a compatible interface to metal oxide semiconductors to form a high-performance active layer. Solution-processed bottom-gate metal oxide TFTs with polymer gate insulators have been inactive or have exhibited poor performance. Moon et al. reported that polymeric gate insulators such as poly(4-vinylphenol), poly(methyl methacrylate), polyimide, and poly(vinyl alcohol) gate insulators are damaged during the post-annealing process of $\mathrm{ZnO}$ semiconductor layers for bottom-gate TFTs. ${ }^{17} \mathrm{Kim}$ et al. reported that a solution-processed bottom-gate zinc oxide TFT with a cross-linked poly(4-vinylphenol) gate insulator, prepared on a flexible PET substrate, exhibited mobility of $0.13 \mathrm{~cm}^{2} \mathrm{~V}^{-1} \mathrm{~s}^{-1} \cdot{ }^{9}$ Recently, we reported the surface modification of high-heat-resistant polyimide gate insulators with an yttrium oxide interlayer for aqueous-solution-processed bottom-gate ZnO TFTs. ${ }^{18}$ By introduction of the interlayer, a coherent interface between the $\mathrm{ZnO}$ semiconductor and the bilayer gate insulator could be obtained. Because an additional interlayer deposition process is required and the obtained field-effect mobility of the ZnO TFT is only $0.456 \mathrm{~cm}^{2} \mathrm{~V}^{-1} \mathrm{~s}^{-1}$, the process and the TFT performance still need to be improved. (In the case of a top-gate structure, Qiu et al. reported that solution-processed top-gate zinc-tin oxide TFTs with poly(methyl methacrylate) gate insulators exhibited mobilities up to $1.8 \mathrm{~cm}^{2} \mathrm{~V}^{-1} \mathrm{~s}^{-1} \cdot{ }^{19}$ )

In this study, we have developed poly(imide-bezoxazole) (K-PIB) gate insulators with high thermal resistance. The electrical insulating property of the K-PIB was maintained up to 
$350{ }^{\circ} \mathrm{C}$. To the best of our knowledge, this is the first report on the polymeric gate insulator with high thermal resistance applicable to solution-processed bottom-gate metal oxide TFTs. The K-PIB gate insulators provide a compatible interface to solution-processed indium-zinc oxide (IZO) semiconductors without any interlayers. Solution-processed bottom-gate IZO TFTs with K-PIB gate insulators showed excellent TFT performance with the field-effect mobility of $9.2 \mathrm{~cm}^{2} \mathrm{~V}^{-1} \mathrm{~s}^{-1}$ and the on/off current ratio of $1.5 \times 10^{6}$. We also fabricated flexible IZO TFTs with the K-PIB gate insulator on a flexible Kapton substrate, which showed excellent TFT performance with the field-effect mobility of $4.1 \mathrm{~cm}^{2} \mathrm{~V}^{-1} \mathrm{~s}^{-1}$ and the on/off current ratio of $4.7 \times 10^{5}$. Interestingly, during bending with a bending radius of $10 \mathrm{~mm}$, the mobility of the flexible IZO TFT was maintained and the on/off current ratio was slightly decreased to $3.2 \times 10^{5}$.

\section{Results and discussion}

We prepared the K-PIB precursor, poly(amic acid-benzoxazole) (K-PAB), from a dianhydride monomer of 4,4'-oxydiphthalic dianhydride (ODPA) and a rigid aromatic diamine monomer with benzoxazole groups (BODA), as shown in Scheme 1. The viscosity of the polymerization solution with a solid content of $20 \mathrm{wt} \%$ reaches the saturation point, $45000 \mathrm{cps}$. The inherent viscosity of $\mathrm{K}-\mathrm{PAB}$ was found to be $1.03 \mathrm{dL} \mathrm{g}^{-1}$. The prepared $\mathrm{K}-\mathrm{PAB} /$ dimethylacetamide (DMAc) polymerization solution was directly spin-coated on the indium tin oxide (ITO) glass, and thermally imidized on a hot-plate in ambient air to obtain K-PIB thin films. Weight loss of the K-PAB due to the thermal imidization was observed by thermal gravimetric analysis (TGA) (Fig. 1). The imidization temperature was found to be $<300{ }^{\circ} \mathrm{C}$. The weight loss between $120^{\circ} \mathrm{C}$ and $300{ }^{\circ} \mathrm{C}$ was measured to be $5.3 \%$, which corresponds to the calculated mass difference between the repeat unit masses of K-PAB and K-PIB. The weight loss at a temperature above $550{ }^{\circ} \mathrm{C}$ is thought to be due to the

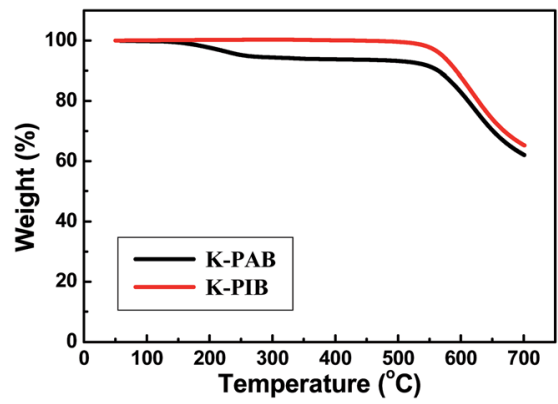

Fig. 1 TGA results of $\mathrm{K}-\mathrm{PAB}$ and $\mathrm{K}-\mathrm{PIB}$.

carbonization of polymers. ${ }^{\text {20-22 }}$ The thermal imidization of K-PAB was also confirmed by IR analysis. The characteristic absorption bands at $1357 \mathrm{~cm}^{-1}$ and $1505 \mathrm{~cm}^{-1}$ are the characteristic imide II band $\left(\nu_{\mathrm{C}-\mathrm{N}}\right)$ and the aromatic ring stretching band $\left(\nu_{\mathrm{C}}={ }_{\mathrm{C}}\right)$, respectively. Fig. 2 shows the annealing temperature-dependent (a) IR spectrum and (b) $\nu_{\mathrm{C}-\mathrm{N}}$ and $\nu_{\mathrm{C}=\mathrm{C}}$ IR absorbance ratio of the K-PIB films. Because the absorbance ratio, which is proportional to the degree of imidization, is saturated at $250{ }^{\circ} \mathrm{C}$, it is expected that $\mathrm{K}-\mathrm{PAB}$ films could be fully imidized at above $250{ }^{\circ} \mathrm{C}$. Based on the TGA and IR analysis, an annealing temperature of $300{ }^{\circ} \mathrm{C}$ was used for the imidization of $\mathrm{K}$-PAB films in this work. K-PIB imidized at $300{ }^{\circ} \mathrm{C}$ showed excellent thermal resistance. The $1 \%$ weight-loss temperature of the K-PIB was measured to be $528{ }^{\circ} \mathrm{C}$ (Fig. 1), which is higher than the conventional processing temperature of metal oxide semiconductors.

Using the metal-insulator-metal (MIM) capacitor structure, the capacitance was measured (Fig. 3a). The capacitance and dielectric constant of the $500 \mathrm{~nm}$-thick K-PIB film were 48.2$50.8 \mathrm{pF} \mathrm{mm}^{-2}$ and $2.7-2.8$, respectively, in the frequency range from $40 \mathrm{~Hz}$ to $100 \mathrm{kHz}$. The $500 \mathrm{~nm}$-thick K-PIB film had a smooth surface, as shown in the atomic force microscopy (AFM) image (Fig. 3b). The surface root-mean-square (rms) roughness,<smiles>Nc1ccc(-c2nc3cc4nc(-c5ccc(N)cc5)oc4cc3o2)cc1</smiles><smiles>C=CC(C)(C)NC(=O)c1cc(Oc2ccc(C(=O)Nc3ccc(-c4nc5cc6nc(-c7ccc(C(C)(C)C)cc7)oc6cc5o4)cc3)c(C(=O)O)c2)ccc1C(=O)O</smiles>

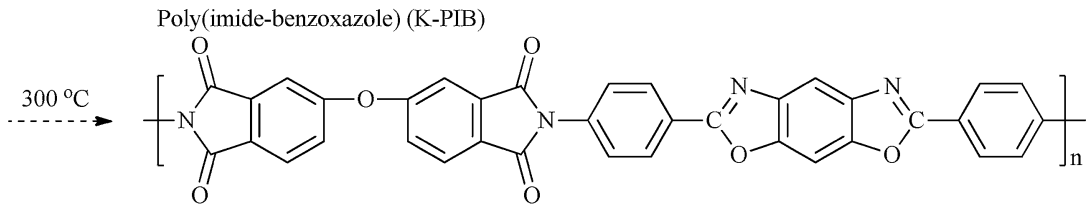

Scheme 1 Synthetic route to a K-PIB gate insulator. 

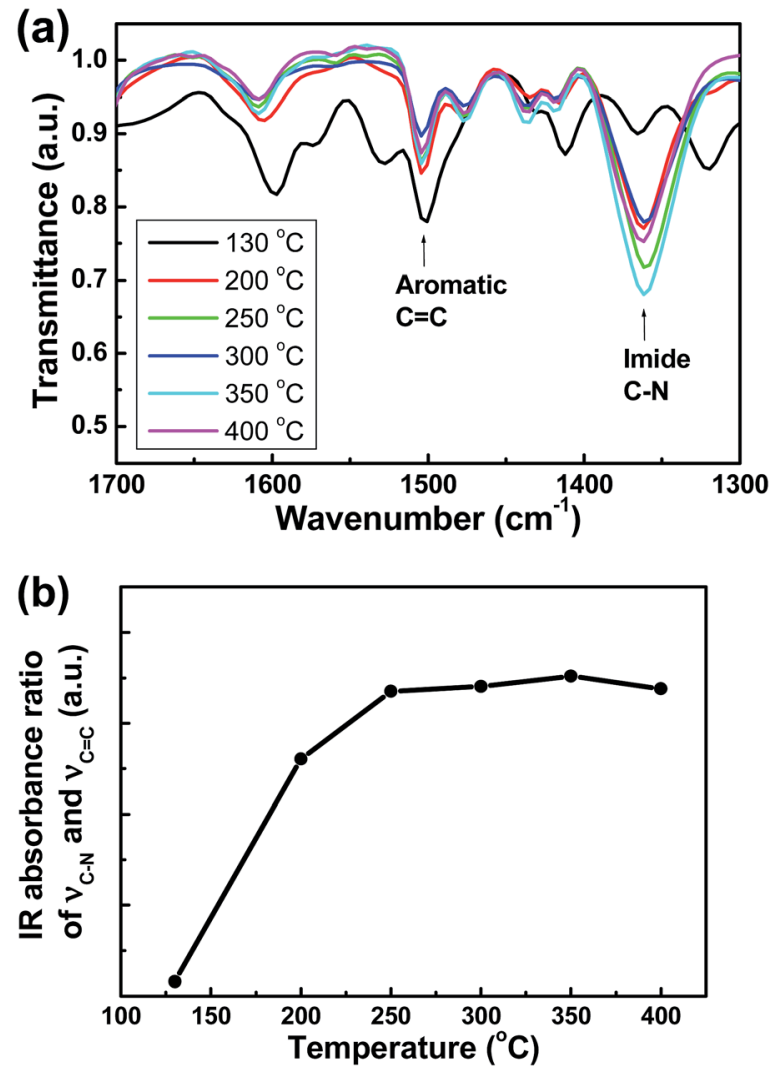

Fig. 2 Annealing temperature-dependent (a) IR spectrum and (b) $\nu_{\mathrm{C}-\mathrm{N}}$ and $\nu_{C}={ }_{C} I R$ absorbance ratio of K-PIB films.

calculated from the AFM image $(5 \mu \mathrm{m} \times 5 \mu \mathrm{m})$ of the K-PIB film, was $0.82 \mathrm{~nm}$. The surface energy of the K-PIB film, calculated from the contact angles of water and diiodomethane, was 50.4 dyn $\mathrm{cm}^{-1}$.

To use the K-PIB film as a gate insulator for solution-processed metal oxide TFTs, its electrical insulating properties after the post-annealing process should be confirmed. The prepared $500 \mathrm{~nm}$-thick K-PIB films were additionally annealed at $300^{\circ} \mathrm{C}$, $350^{\circ} \mathrm{C}$ and $400^{\circ} \mathrm{C}$, respectively, for $2 \mathrm{~h}$ on a hot-plate in ambient air. Fig. 4 shows the electric field-dependent leakage current densities of $500 \mathrm{~nm}$-thick K-PIB films after post-annealing at $300{ }^{\circ} \mathrm{C}, 350{ }^{\circ} \mathrm{C}$ and $400{ }^{\circ} \mathrm{C}$. The $300{ }^{\circ} \mathrm{C}$ and $350{ }^{\circ} \mathrm{C}$-annealed $\mathrm{K}$-PIB films showed excellent insulating properties. The leakage current densities of both the films were measured to be less than $2.3 \times 10^{-10} \mathrm{~A} \mathrm{~cm}^{-2}$ while biased from 0 to $1.8 \mathrm{MV} \mathrm{cm}^{-1}$. However, after annealing at $400{ }^{\circ} \mathrm{C}$, the leakage current density of the K-PIB film dramatically increased. The leakage current density was measured to be $1.2 \times 10^{-5} \mathrm{~A} \mathrm{~cm}^{-2}$ at $1.8 \mathrm{MV} \mathrm{cm}^{-1}$. Although there is no weight loss at $400{ }^{\circ} \mathrm{C}$ in the TGA result, the heat treatment could affect the electrical insulating property of K-PIB. It is expected that K-PIB is stable up to at least $3500^{\circ} \mathrm{C}$ and applicable to solution-processed metal oxide TFTs in terms of thermal stability and electrical insulating property.

For comparison, we also prepared the polyimide (K-PI) precursor, the poly(amic acid) (K-PAA) from a dianhydride monomer of ODPA and a diamine monomer of
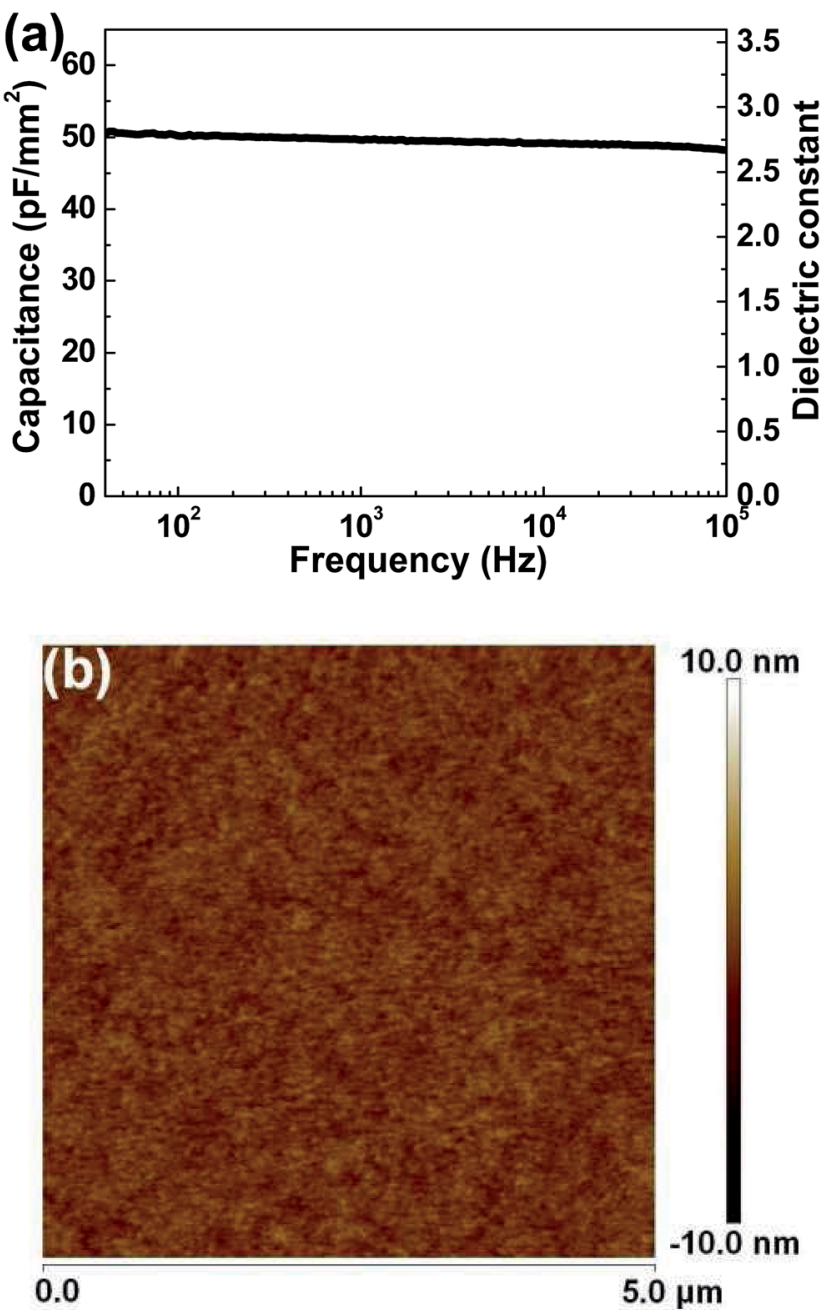

Fig. 3 (a) Frequency-dependent capacitance and (b) AFM image $(5 \mu \mathrm{m}$ $\times 5 \mu \mathrm{m})$ of the $500 \mathrm{~nm}$-thick K-PIB film.

$p$-phenylenediamine ( $p$-PDA) instead of BODA (Scheme S2 $\dagger$ ). Fig. $\mathrm{S} 1 \uparrow$ shows the electric field-dependent leakage current densities of $300{ }^{\circ} \mathrm{C}, 350{ }^{\circ} \mathrm{C}$ and $400{ }^{\circ} \mathrm{C}$-annealed $500 \mathrm{~nm}$-thick K-PI films. While biased from 0 to $1.8 \mathrm{MV} \mathrm{cm}^{-1}$, the leakage current density of the $300^{\circ} \mathrm{C}$-annealed K-PI film was measured to be less than $3.7 \times 10^{-6} \mathrm{~A} \mathrm{~cm}^{-2}$, which is much higher than that of the $300{ }^{\circ} \mathrm{C}$-annealed K-PIB film. There is no weight loss of K-PI at $350{ }^{\circ} \mathrm{C}$ and at $400{ }^{\circ} \mathrm{C}$ (Fig. S2 $\dagger$ ). However, electrical breakdown was observed in the $350{ }^{\circ} \mathrm{C}$ and $400{ }^{\circ} \mathrm{C}$-annealed K-PI films. Polyimides are well-known to have excellent thermal stability and electrical insulating property that are strongly related to the chain packing. ${ }^{23-25}$ Use of the BODA with a longer rigid core as a diamine monomer might be advantageous to the polymer chain packing, and it might affect the thermal stability and gate insulating property of the polymer film.

To investigate the potential of the K-PIB film as a gate insulator, solution-processed IZO TFTs with K-PIB gate insulators on a glass substrate or a flexible Kapton substrate were fabricated. Solution-processed IZO TFTs are known to have excellent TFT performance and long-term stability in 


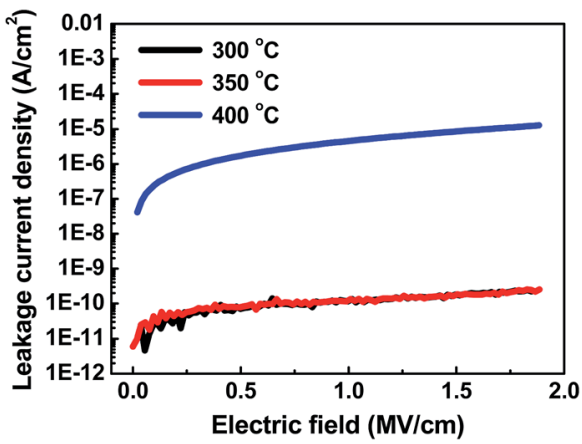

Fig. 4 Electric field-dependent leakage current densities of $500 \mathrm{~nm}$ thick K-PIB films after post-annealing at $300^{\circ} \mathrm{C}, 350{ }^{\circ} \mathrm{C}$ and $400{ }^{\circ} \mathrm{C}$.

amorphous structures. We chose a recently reported simple method for the amorphous IZO deposition in which the precursor solution is composed of zinc nitrate, indium acetylacetonate and 2-methoxyethanol. ${ }^{16}$ Cho et al. reported that $350{ }^{\circ} \mathrm{C}$-annealed IZO TFTs with $\mathrm{SiO}_{2}$ gate insulators exhibited mobilities up to $13.8 \mathrm{~cm}^{2} \mathrm{~V}^{-1} \mathrm{~s}^{-1} \cdot{ }^{16}$ Although amorphous IZO channel layers with a smooth surface were well-formed on $\mathrm{SiO}_{2}$ gate insulators, the formation on K-PIB gate insulators should be confirmed for the TFT application.

The chemical structure of the IZO layer on the K-PIB gate insulator was studied by X-ray photoelectron spectroscopy (XPS) to verify the formation of the oxide skeleton framework. Fig. 5a shows the $\mathrm{O} 1 \mathrm{~s}$ XPS spectra of the $350^{\circ} \mathrm{C}$-annealed IZO layer on the K-PIB gate insulator. The three XPS peaks centered at 528.8, 530.6 , and $531.8 \mathrm{eV}$ indicate an oxide lattice surrounded by In and $\mathrm{Zn}$ atoms, an oxygen-deficient lattice, that is, an oxide lattice with an oxygen vacancy, and the oxygen in the hydroxide, respectively. ${ }^{26-29}$ It is clear that the oxide skeleton forms with the presence of a small amount of hydroxide, which is also observed
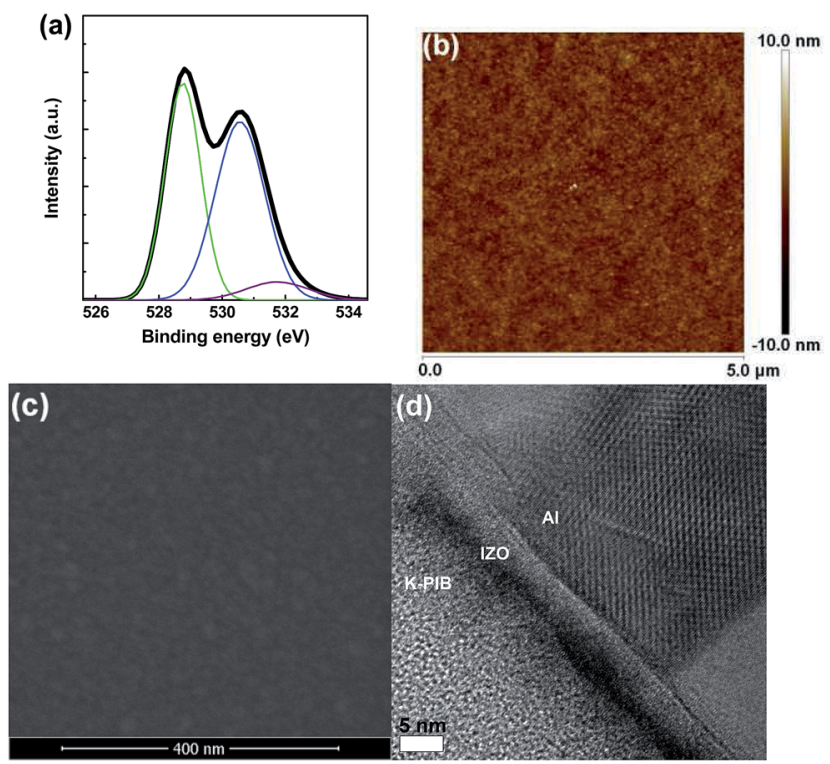

Fig. 5 (a) XPS spectrum, (b) AFM image $(5 \mu \mathrm{m} \times 5 \mu \mathrm{m})$, (c) SEM image and (d) cross-sectioned TEM image of the IZO layer on the K-PIB film. in the IZO layer on the $\mathrm{SiO}_{2}$ gate insulator. ${ }^{16}$ The $350{ }^{\circ} \mathrm{C}$ annealed IZO layer on the K-PIB gate insulator is thought to be amorphous as confirmed by X-ray diffraction (XRD) analysis (Fig. S3 $\uparrow$ ). It is reported that the solution-processed IZO thin films showed amorphous nature after annealing at 200$450{ }^{\circ} \mathrm{C} .11,16,30,31$

Fig. $5 \mathrm{~b}$ shows an AFM image of the $350^{\circ} \mathrm{C}$-annealed IZO layer on the K-PIB gate insulator. On the K-PIB gate insulator, an IZO layer with a smooth surface was well-formed. The surface rms roughness, measured in an area of $5 \mu \mathrm{m} \times 5 \mu \mathrm{m}$, was $0.99 \mathrm{~nm}$, which is comparable to that of the K-PIB gate insulator, $0.82 \mathrm{~nm}$. The smooth surface of the IZO layer on the K-PIB gate insulator was also observed by scanning electron microscopy (SEM) (Fig. 5c). Formation of a coherent interface between the IZO semiconductor and the K-PIB gate insulator was confirmed by transmission electron microscopy (TEM) (Fig. 5d and Fig. $\mathrm{S} 4 \uparrow$ ). An amorphous $5 \mathrm{~nm}$-thick IZO layer on the K-PIB gate insulator was observed in the cross-sectioned TEM images. Formation of the coherent interface might be related to the precursor solution wettability of the K-PIB film and the amorphous nature of the IZO layer. The contact angle of 2-methoxyethanol, the solvent for the IZO precursor solution, on the K-PIB film is less than $5^{\circ}$. The amorphous structure might prevent the formation of pores and cracks during the annealing process.

Fig. 6 shows the transfer characteristics $\left(I_{\mathrm{ds}} v s . V_{\mathrm{gs}}\right)$ of the $300{ }^{\circ} \mathrm{C}, 350{ }^{\circ} \mathrm{C}$ and $400{ }^{\circ} \mathrm{C}$-annealed IZO TFTs with K-PIB gate insulators. The solution-processed TFTs showed excellent TFT performance. The electrical performance parameters, namely, mobility, on/off current ratio $\left(I_{\text {on }} / I_{\text {off }}\right)$, subthreshold slope (S-slope) and threshold voltage $\left(V_{\text {th }}\right)$ are summarized in Table 1. The $300{ }^{\circ} \mathrm{C}, 350{ }^{\circ} \mathrm{C}$ and $400{ }^{\circ} \mathrm{C}$-annealed IZO TFTs with K-PIB gate insulators exhibited mobilities up to $6.0,9.0$ and $11.2 \mathrm{~cm}^{2}$ $\mathrm{V}^{-1} \mathrm{~s}^{-1}$, respectively. In general, more complete formation of the M-O-M bonds and higher mobility of the TFTs are expected at the higher annealing temperature of metal oxide semiconductors. However, the off current of the $400{ }^{\circ} \mathrm{C}$-annealed IZO TFT is much higher than those of the $300{ }^{\circ} \mathrm{C}$ and $350{ }^{\circ} \mathrm{C}$ -

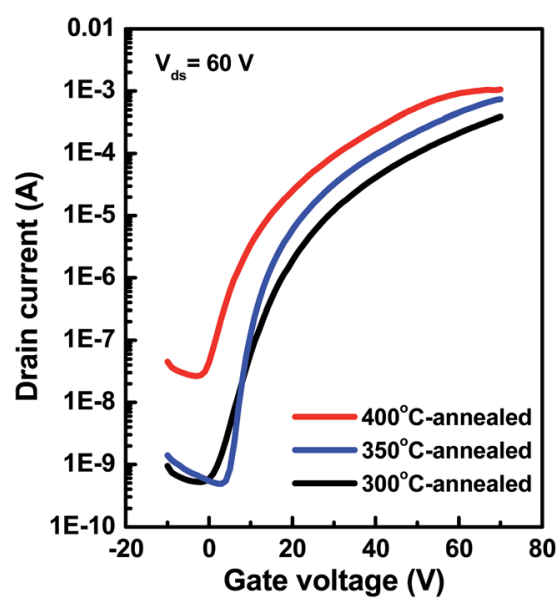

Fig. 6 Transfer characteristics $\left(I_{\text {ds }} v s . V_{\text {gs }}\right)$ of the $300^{\circ} \mathrm{C}, 350{ }^{\circ} \mathrm{C}$ and $400{ }^{\circ} \mathrm{C}$-annealed IZO TFTs with $\mathrm{K}$-PIB gate insulators. 
Table 1 Electrical performance parameters of the IZO TFTs with K-PIB gate insulators

Channel length $(L)=50 \mu \mathrm{m}$ and channel width $(W)=1000 \mu \mathrm{m}$

\begin{tabular}{lllll}
$\begin{array}{l}\text { IZO annealing } \\
\text { temperature }\left[{ }^{\circ} \mathrm{C}\right]\end{array}$ & $\begin{array}{l}\text { Mobility } \\
{\left[\mathrm{cm}^{2} \mathrm{~V}^{-1} \mathrm{~s}^{-1}\right]}\end{array}$ & $I_{\text {on }} / I_{\text {off }}$ & $\begin{array}{l}\text { S-slope } \\
{[\mathrm{V} \text { per decade }]}\end{array}$ & $\begin{array}{l}V_{\text {th }} \\
{[\mathrm{V}]}\end{array}$ \\
\hline 300 & 6.0 & $7.1 \times 10^{5}$ & 4.6 & 31.3 \\
350 & 9.2 & $1.5 \times 10^{6}$ & 2.0 & 26.5 \\
400 & 11.2 & $3.8 \times 10^{4}$ & 4.4 & 18.8
\end{tabular}

annealed IZO TFTs. The higher off current value is due to the reduced electrical insulating property of the K-PIB gate insulator, post-annealed at $400{ }^{\circ} \mathrm{C}$, as shown in Fig. 4 . Rolland et al. reported that the upper limit of density of interfacial trap states could be extracted from the subthreshold slope. ${ }^{32}$ (The calculation method was described elsewhere. ${ }^{32-35}$ ) The estimated upper limits of the $300{ }^{\circ} \mathrm{C}, 350{ }^{\circ} \mathrm{C}$ and $400{ }^{\circ} \mathrm{C}$-annealed K-PIB gate insulators are $2.4 \times 10^{12}, 1.0 \times 10^{12}$ and $2.3 \times 10^{12} \mathrm{~cm}^{-2}$ $\mathrm{eV}^{-1}$, respectively. Overall, the $350{ }^{\circ} \mathrm{C}$-annealed IZO TFT with the K-PIB gate insulator showed the best performance. To obtain the average and standard deviations of the electrical performance parameters, we prepared twenty $350{ }^{\circ} \mathrm{C}$-annealed IZO TFTs with K-PIB gate insulators (Table 2). The average mobility, threshold voltage, and subthreshold slope were measured to be $5.5 \pm 1.5 \mathrm{~cm}^{2} \mathrm{~V}^{-1} \mathrm{~s}^{-1}, 24.0 \pm 3.8 \mathrm{~V}$, and $3.0 \pm$ $0.8 \mathrm{~V}$ per decade, respectively. Also, their on/off current ratios were in the range from $2.3 \times 10^{5}$ to $1.5 \times 10^{6}$. The output

Table 2 Average electrical performance parameters of the twenty $350{ }^{\circ} \mathrm{C}$-annealed IZO TFTs with $\mathrm{K}$-PIB gate insulators

Channel length $(L)=50 \mu \mathrm{m}$ and channel width $(W)=1000 \mu \mathrm{m}$

\begin{tabular}{llll}
\hline Mobility & & S-slope \\
{$\left[\mathrm{cm}^{2} \mathrm{~V}^{-1} \mathrm{~s}^{-1}\right]$} & $I_{\text {on }} / I_{\text {off }}$ & {$[\mathrm{V}$ per decade $]$} & $V_{\text {th }}[\mathrm{V}]$ \\
\hline
\end{tabular}

$5.5 \pm 1.5$

$2.3 \times 10^{5}$ to $1.5 \times 10^{6} \quad 3.0 \pm 0.8$

$24.0 \pm 3.8$

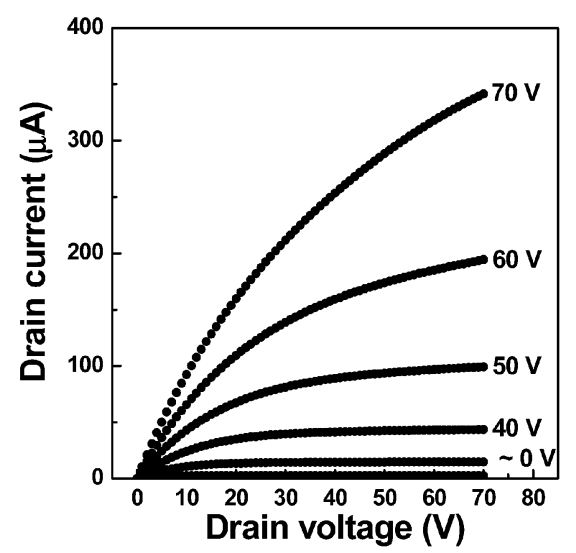

Fig. 7 Output characteristics $\left(I_{\text {ds }}\right.$ vs. $\left.V_{\text {ds }}\right)$ of the $350{ }^{\circ} \mathrm{C}$-annealed IZO TFT. characteristics $\left(I_{\mathrm{ds}} v s . \quad V_{\mathrm{ds}}\right)$ of the $350{ }^{\circ} \mathrm{C}$-annealed IZO TFT shows clear linear and saturation regions (Fig. 7).

To verify the feasibility of the solution-processed flexible TFT, we fabricated $350{ }^{\circ} \mathrm{C}$-annealed IZO TFT with the K-PIB gate insulator directly on a $120 \mu \mathrm{m}$-thick flexible Kapton substrate (Fig. 8a). The output characteristics $\left(I_{\mathrm{ds}} v s . V_{\mathrm{ds}}\right)$ of the IZO TFT on a Kapton substrate shows clear linear and saturation regions (Fig. 8b). Fig. 8c shows the transfer characteristics $\left(I_{\mathrm{ds}} v s . V_{\mathrm{gs}}\right)$ of the IZO TFT with the K-PIB gate insulator on a flexible Kapton
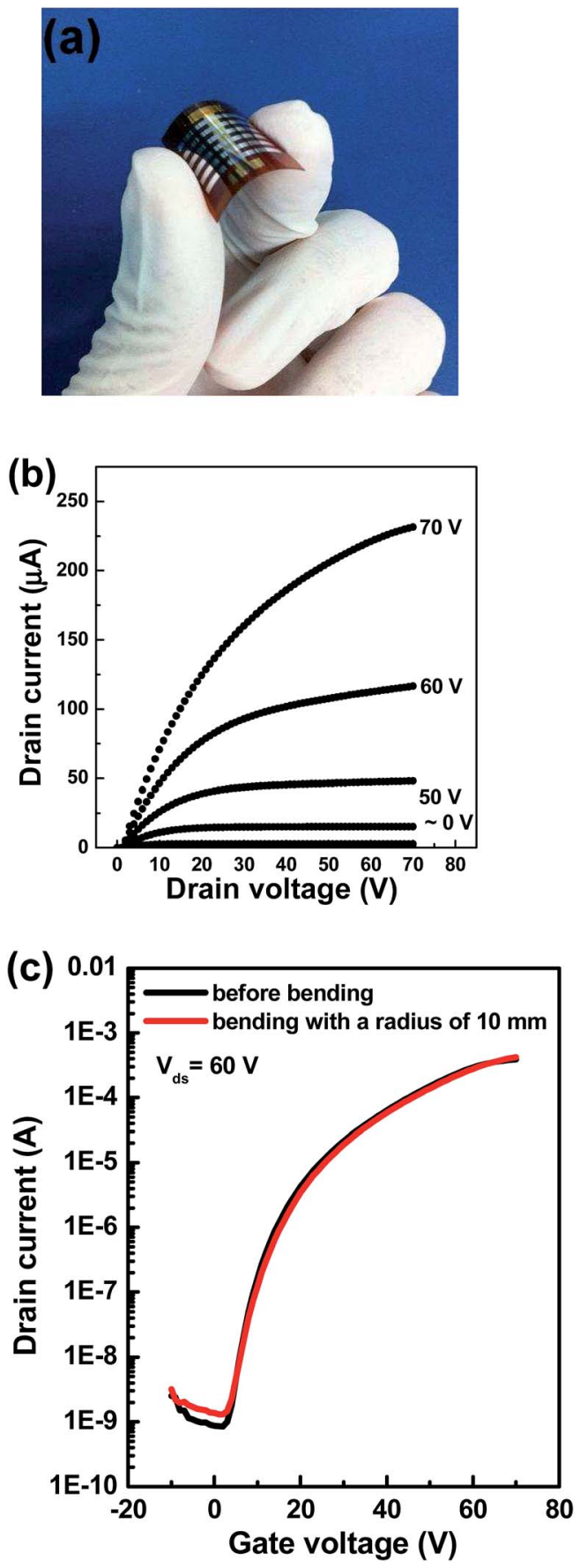

Fig. 8 (a) Photograph, (b) output characteristics ( $I_{\text {ds }}$ vs. $\left.V_{\text {ds }}\right)$ and (c) transfer characteristics $\left(I_{\mathrm{ds}} v \mathrm{vs} . V_{\mathrm{gs}}\right)$ of the $350^{\circ} \mathrm{C}$-annealed flexible IZO TFT on a Kapton substrate. 
Table 3 Electrical performance parameters of the flexible IZO TFT with K-PIB gate insulator fabricated directly on a flexible Kapton substrate

Channel length $(L)=50 \mu \mathrm{m}$ and channel width $(W)=1000 \mu \mathrm{m}$

\begin{tabular}{lllll}
$\begin{array}{l}\text { Bending } \\
\text { radius }[\mathrm{mm}]\end{array}$ & $\begin{array}{l}\text { Mobility } \\
{\left[\mathrm{cm}^{2} \mathrm{~V}^{-1} \mathrm{~s}^{-1}\right]}\end{array}$ & $I_{\text {on }} / I_{\text {off }}$ & $\begin{array}{l}\text { S-slope } \\
{[\mathrm{V} \text { per decade }]}\end{array}$ & $\begin{array}{l}V_{\text {th }} \\
{[\mathrm{V}]}\end{array}$ \\
\hline$\infty$ & 4.1 & $4.7 \times 10^{5}$ & 2.7 & 22.8 \\
10 & 4.1 & $3.2 \times 10^{5}$ & 3.0 & 23.0
\end{tabular}

substrate before bending and during bending with a radius of $10 \mathrm{~mm}$. The flexible TFT shows excellent TFT performance (Table 3). Before bending, the mobility, on/off current ratio, subthreshold slope, and threshold voltage were $4.1 \mathrm{~cm}^{2} \mathrm{~V}^{-1} \mathrm{~s}^{-1}$, $4.7 \times 10^{5}, 2.7 \mathrm{~V}$ per decade, and $22.8 \mathrm{~V}$, respectively. Interestingly, no significant reduction in TFT performance was observed during bending, as shown in Fig. 8c. During bending with a radius of $10 \mathrm{~mm}$, the mobility, on/off current ratio, subthreshold slope, and threshold voltage were $4.1 \mathrm{~cm}^{2} \mathrm{~V}^{-1} \mathrm{~s}^{-1}$, $3.2 \times 10^{5}, 3.0 \mathrm{~V}$ per decade, and $23.0 \mathrm{~V}$, respectively. Our results indicate that the IZO TFT with the K-PIB gate insulator can operate during bending. We believe that the K-PIB gate insulator is an attractive candidate for solution-processed flexible metal oxide TFTs.

\section{Conclusion}

We report a poly(imide-benzoxazole) gate insulator with high thermal resistance for solution-processed flexible metal oxide TFTs. To investigate the potential of the poly(imide-benzoxazole) as a gate insulator, we fabricated solution-processed IZO TFTs. The $350{ }^{\circ} \mathrm{C}$-annealed IZO TFT with the K-PIB gate insulator showed excellent TFT performance with the field-effect mobility of $9.2 \mathrm{~cm}^{2} \mathrm{~V}^{-1} \mathrm{~s}^{-1}$ and the on/off current ratio of $1.5 \times$ $10^{6}$. We also fabricated flexible IZO TFTs with the K-PIB gate insulator, which showed excellent TFT performance with the field-effect mobility of $4.1 \mathrm{~cm}^{2} \mathrm{~V}^{-1} \mathrm{~s}^{-1}$ and the on/off current ratio of $4.7 \times 10^{5}$. Interestingly, during bending with a bending radius of $10 \mathrm{~mm}$, the TFT performance of the flexible IZO TFT was maintained. Our results indicate that the poly(imide-benzoxazole) gate insulator is applicable for high-performance, solution-processed flexible metal oxide TFTs.

\section{Experimental}

We prepared a rigid aromatic diamine monomer, BODA, from diaminodihydroxybenzene dihydrochloride (DADHB) and aminobenzoic acid (ABA) for polymerization of the K-PIB (Scheme $\mathrm{S} 1 \dagger$ ). Then, $0.011 \mathrm{~mol}$ of DADHB was added to $50 \mathrm{~g}$ of polyphosphoric acid (PPA). After the solution was vigorously stirred at $100{ }^{\circ} \mathrm{C}$ for $2 \mathrm{~h}, 0.022 \mathrm{~mol}$ of ABA was added and the solution was vigorously stirred at $120{ }^{\circ} \mathrm{C}$ for $4 \mathrm{~h}$. The solution temperature was raised to $150{ }^{\circ} \mathrm{C}$ at a rate of $30^{\circ} \mathrm{C} \mathrm{h}^{-1}$ and to $170{ }^{\circ} \mathrm{C}$ at a rate of $20^{\circ} \mathrm{C} \mathrm{h}^{-1}$. After vigorously stirring for $2 \mathrm{~h}, 500 \mathrm{ml}$ of DI water was added. The precipitates were washed repeatedly with $5 \mathrm{wt} \% \mathrm{NaHCO}_{3}$ aqueous solution and DI water. After the dried product was dissolved in $20 \mathrm{ml}$ of dimethyl sulfoxide, the solution was added dropwise to $500 \mathrm{ml}$ of toluene. The precipitated product was washed with toluene and dried in vacuo at $80{ }^{\circ} \mathrm{C}$.

We prepared the K-PIB precursor, the K-PAB from monomers of ODPA and BODA (Scheme 1). In DMAc, $0.01 \mathrm{~mol}$ of ODPA and $0.01 \mathrm{~mol}$ of BODA were dissolved. The total concentration of the monomers was $20 \mathrm{wt} \%$. The solution was stirred until the solution viscosity reached the saturation point. ITO-coated glass was used as a substrate and the ITO was patterned to produce an electrode with the conventional photolithographic method: coating with a photoresist and ultraviolet light exposure followed by developing and etching. The patterned ITO substrate was cleaned using a typical cleaning process for electronic applications: sonication in detergent, deionized water, acetone, and isopropanol in that order for $20 \mathrm{~min}$ at room temperature. The K-PAB solution was spin-coated on patterned ITO-coated glasses. The spin-coated films were annealed at $90{ }^{\circ} \mathrm{C}$ for $10 \mathrm{~min}$ and $300{ }^{\circ} \mathrm{C}$ for $40 \mathrm{~min}$ on a hot-plate in ambient air. The final thickness of the K-PIB films was controlled to be $500 \mathrm{~nm}$.

To determine the capacitance and the leakage current density of the gate insulators, MIM capacitor structures were prepared by deposition of the top gold electrode on the gate insulator-coated ITO glass. The active area of the MIM devices was $50.24 \mathrm{~mm}^{2}$. For electrical characterizations, we prepared bottom-gate, top-contact TFT devices. ITO-coated glass or a gold-coated Kapton film was used as a substrate. The ITO and the gold were patterned ( $2 \mathrm{~mm}$ wide stripes) to produce the gate electrode. To prepare the IZO precursor solution, $0.05 \mathrm{M}$ zinc acetylacetonate hydrate $\left(\mathrm{Zn}\left(\mathrm{C}_{5} \mathrm{H}_{7} \mathrm{O}_{2}\right)_{2} \cdot \mathrm{xH}_{2} \mathrm{O}\right)$ and $0.05 \mathrm{M}$ indium nitrate hydrate $\left(\mathrm{In}\left(\mathrm{NO}_{3}\right)_{3} \cdot x \mathrm{H}_{2} \mathrm{O}\right)$ were dissolved in anhydrous 2-methoxyethanol. After spin-coating of the IZO precursor solution on the K-PIB gate insulator at $4000 \mathrm{rpm}$ for $30 \mathrm{~s}$, the film was annealed at $90^{\circ} \mathrm{C}$ for $10 \mathrm{~min}$ and $300^{\circ} \mathrm{C}$ for $2 \mathrm{~h}$ on a hot-plate in ambient air. After the annealing process, a $100 \mathrm{~nm}$-thick aluminum source and drain electrodes were deposited by thermal evaporation on the semiconductor layer through a shadow mask, creating transistors with a channel length $(L)$ and a width $(W)$ of 50 and $1000 \mu \mathrm{m}$, respectively.

The capacitance was measured with an Agilent $4294 \mathrm{~A}$ impedance analyzer. The transfer $\left(I_{\mathrm{ds}} \quad v s . \quad V_{\mathrm{gs}}\right)$ and output $\left(I_{\mathrm{ds}} v s . V_{\mathrm{ds}}\right)$ characteristics of the TFT s were measured with an Agilent E5272 semiconductor parameter analyzer. All these electrical measurements were carried out in air without any encapsulation. XRD analysis was performed using a thin film diffraction in which samples were fixed at an angle of $3^{\circ}$ to the X-ray beam with $2 \theta$ scan of the detector. XPS analysis was performed on an AXIS Nova spectrometer (Kratos Analytical) using a monochromatic an $\mathrm{Al} \mathrm{K} \alpha$ source $(h \nu=1486.6 \mathrm{eV})$ at a power of 140-150 W. The XPS spectrum was obtained without any treatment. The spectrum was recorded applying a pass energy of $40 \mathrm{eV}$ with an energy resolution of $0.8 \mathrm{eV}$. The analysis spot size was $400 \mu \mathrm{m} \times 800 \mu \mathrm{m}$ and the vacuum below $10^{-8}$ Torr for the measurement. 


\section{Acknowledgements}

This work was supported by a grant from the cooperative R\&D program funded by the Korea Research Council for Industrial Science and Technology and was partially supported by the KRICT core project (KK-1402-C0) funded by the Ministry of Knowledge Economy.

\section{References}

1 J. H. Cho, J. Lee, Y. Xia, B. Kim, Y. He, M. J. Renn, T. P. Lodge and C. D. Frisbie, Nat. Mater., 2008, 7, 900.

2 M. E. Roberts, N. Queroltó, S. C. B. Mannsfeld, B. N. Reinecke, W. Knoll and Z. Bao, Chem. Mater., 2009, 21, 2292.

3 Z. Liu, J. H. Oh, M. E. Roberts, P. Wei, B. C. Paul, M. Okajima, Y. Nishi and Z. Bao, Appl. Phys. Lett., 2009, 94, 203301.

4 S. C. B. Mannsfeld, B. C.-K. Tee, R. M. Stoltenberg, C. V. H.-H. Chen, S. Barman, B. V. O. Muir, A. N. Sokolov, C. Reese and Z. Bao, Nat. Mater., 2010, 9, 859.

5 A. Sokolov, Y. Cao, O. B. Johnson and Z. Bao, Adv. Funct. Mater., 2012, 22, 175.

6 K.-J. Baeg, D. Khim, S.-W. Jung, M. Kang, I.-K. You, D.-Y. Kim, A. Facchetti and Y.-Y. Noh, Adv. Mater., 2012, 24, 5433.

7 J.-Y. Yoon, S. Jeong, S. S. Lee, Y. H. Kim, J.-W. Ka, M. H. Yi and K.-S. Jang, ACS Appl. Mater. Interfaces, 2013, 5, 5149.

8 P. K. Nayak, J. Kim, C. Lee and Y. Hong, Phys. Status Solidi A, 2010, 207, 1664.

9 K. Kim, S. Park, J.-B. Seon, K.-H. Lim, K. Char, K. Shin and Y. S. Kim, Adv. Funct. Mater., 2011, 21, 3546.

10 M.-G. Kim, M. G. Kanatzidis, A. Facchetti and T. J. Marks, Nat. Mater., 2011, 10, 382.

11 K. K. Banger, Y. Yamashita, K. Mori, R. L. Peterson, T. Leedham, J. Rickard and H. Sirringhaus, Nat. Mater., 2011, 10, 45.

12 S. Jeong, Y.-G. Ha, J. Moon, A. Facchetti and T. J. Marks, Adv. Mater., 2010, 22, 1346.

13 S.-Y. Han, G. S. Herman and C.-H. Chang, J. Am. Chem. Soc., 2011, 133, 5166.

14 M.-G. Kim, H. S. Kim, Y.-G. Ha, J. He, M. G. Kanatzidis, A. Facchetti and T. J. Marks, J. Am. Chem. Soc., 2010, 132, 10352.

15 S. Y. Park, B. J. Kim, K. Kim, M. S. Kang, K.-H. Lim, T. I. Lee, J. M. Myoung, H. K. Baik, J. H. Cho and Y. S. Kim, Adv. Mater., 2012, 24, 834.
16 Y. H. Kang, S. Jeong, J. M. Ko, J.-Y. Lee, Y. Choi, C. Lee and S. Y. Cho, J. Mater. Chem. C, 2014, 2, 4247.

17 Y. Jung, T. Jun, A. Kim, K. Song, T. H. Yeo and J. Moon, J. Mater. Chem., 2011, 21, 11879.

18 K.-S. Jang, D. Wee, Y. H. Kim, J. Kim, T. Ahn, J.-W. Ka and M. H. Yi, Langmuir, 2013, 29, 7143.

19 Y. Zhao, G. Dong, L. Duan, J. Qiao, D. Zhang, L. Wang and Y. Qiu, RSC Adv., 2012, 2, 5307.

20 M. Inagaki, S. Harada, T. Sato, T. Nakajima, Y. Horino and K. Morita, Carbon, 1989, 27, 253.

21 M. Inagaki, Carbon, 1991, 29, 1239.

22 Y. Hishiyama, A. Yoshida and Y. Kaburagi, Carbon, 1992, 30, 333.

23 T. Ahn, J. W. Kim, Y. Choi and M. H. Yi, Org. Electron., 2008, 9, 711.

24 J. Y. Kim, M. H. Yi and T. Ahn, Thin Solid Films, 2010, 518, 6280.

25 K.-S. Jang, W. S. Kim, J.-M. Won, Y.-H. Kim, S. Myung, J.-W. Ka, J. Kim, T. Ahn and M. H. Yi, Phys. Chem. Chem. Phys., 2013, 15, 950.

26 J. C. C. Fan and J. B. Goodenough, J. Appl. Phys., 1997, 48, 3524.

27 S. Major, S. Kumar, M. Bhatnagar and K. L. Chopra, Appl. Phys. Lett., 1986, 49, 394.

28 T. Ishida, H. Kobayashi and Y. Nakato, J. Appl. Phys., 1993, 73, 4344.

29 E. M. C. Fourunato, L. M. N. Pereira, P. M. C. Barquinha, A. M. Bothlho do Rego, G. Goncalves, A. Vila, J. R. Moran and R. F. P. Martins, Appl. Phys. Lett., 2008, 92, 222103.

30 R. C. Hoffmann, M. Kaloumenos, S. Heinschke, E. Erdem, P. Jakes, R.-A. Eichel and J. J. Schneider, J. Mater. Chem. C, 2013, 1, 2577.

31 C. Y. Koo, K. Song, T. Jun, D. Kim, Y. Jeong, S.-H. Kim, J. Ha and J. Moon, J. Electrochem. Soc., 2010, 157, J111.

32 A. Rolland, J. Richard, J. P. Kleider and D. Mencaraglia, J. Electrochem. Soc., 1993, 140, 3679.

33 M. McDowell, I. G. Hill, J. E. McDermott, S. L. Bernasek and J. Schwartz, Appl. Phys. Lett., 2006, 88, 073505.

34 A. Petritz, A. Wolfberger, A. Fian, J. R. Krenn, T. Griesser and B. Stadlober, Org. Electron., 2013, 14, 3070.

35 J.-Y. Yoon, Y. H. Kim, J.-W. Ka, S.-K. Hong, M. H. Yi and K.-S. Jang, J. Mater. Chem. C, 2014, 2, 2191. 